\title{
Pain Therapy in Children and Adolescents
}

\author{
Boris Zernikow, Tanja Hechler
}

\section{SUMMARY}

Introduction: In children, acute pain occurs predominantly during infectious illnesses or after surgery. Chronic pain, especially headache and abdominal pain, is becoming increasingly common among children and adolescents.

Methods: Selective literature review, also including evidence-based guidelines and recommendations.

Results: Simple self-reporting and behavioral pain scales are easy to use to assess the intensity of acute pain. To evaluate chronic pain, on the other hand, more complicated, multi-dimensional instruments are necessary (e.g., semistructured interviews). The most commonly used analgesics are ibuprofen and paracetamol (acetaminophen). When paracetamol is used, its narrow therapeutic window should be kept in mind. Perioperative pain should be treated with balanced analgesia involving a combination of nonpharmacological treatment strategies, non-opioid drugs, opioids, and regional anesthesia. Chronic pain in children can only be treated successfully over the long term with multidisciplinary team intervention based on this biopsychosocial model.

Discussion: Pain not only causes children momentary suffering but also threatens to impair their normal development. Therefore, every effort should be made to prevent pain and to treat it effectively once it arises.

Dtsch Arztebl Int 2008; 105(28-29): 511-22 DOI: 10.3238/arztebl.2008.0511

Key words: pain, children, adolescents, pain scale, medication, treatment

Vodafone Stiftungsinstitut für Kinderschmerztherapie und Pädiatrische Palliativmedizin, Vestische Kinder- und Jugendklinik, Universität Witten/Herdecke: PD Dr. med. Boris Zernikow, Dr. rer. nat. Dipl.-Psych. Tanja Hechler n children, acute pain occurs predominantly during infectious illnesses, painful interventions or after surgery (e1). Chronic pain generally takes the form of headache and abdominal pain, usually with several reported pain locations $(1, \mathrm{e} 2)$. In this article the authors confine themselves to the most common painful conditions. The learning goals are:

- Differentiating the various presentations and causes of pain

- Becoming familiarized with assessment tools and measures for assessing pain in children of all age groups (infants to adolescents) with acute and chronic pain

- Internalizing the principles of pain therapy adapted to children's age and type of pain.

A separate article devoted to painful interventions will be published at a later date.

The methodological basis of this article was a selective literature review mainly in the Medline database (via PubMed), confined to original articles in German and English, systematic reviews, and evidence-based meta-analyses. The Cochrane Database was also consulted. Unless otherwise indicated, the evidence level is stated as specified by the Oxford Centre of Evidencebased Medicine (Version: May 2001) (www.cebm.net) (table 6).

\section{Acute pain}

A large number of acute diseases of childhood (otitis media, pharyngitis, burns, aphthous stomatitis, etc.) are associated with pain. Pain and fever are the commonest causes of an unscheduled pediatric consultation (e3). Almost half the children suffering from otitis media experience severe pain; the mean pain score is 7.5 on a visual analog scale of 0 to 10 (VAS $0-10$ ); $0=$ no pain, $10=$ maximal pain) (e4). The mean duration of pain can be significantly, but only inconsiderably reduced by antibiotic treatment: from 3.3 to 2.8 days (e5). Antibiotic therapy has little influence on pain intensity in the first

\section{Pain in children}

In children, acute pain occurs predominantly during infectious illnesses, painful interventions, or after surgery. Chronic pain most commonly takes the form of headache and abdominal pain. 


\begin{tabular}{|c|c|c|c|}
\hline $\begin{array}{l}\text { Only one statement is } \\
\text { allowed for each }\end{array}$ & TABLE 1 & & \\
\hline $\begin{array}{r}\text { variable. The } \\
\text { observation period is }\end{array}$ & Childhood Discom & fort and Pain (KUSS) Scale* & \\
\hline from this time window & Observation & Rating & Points \\
\hline $\begin{array}{r}\text { are to be recorded, } \\
\text { even if the child's } \\
\text { behavior subsequently } \\
\text { changes. Repeated }\end{array}$ & Crying & $\begin{array}{l}\text { Not at all } \\
\text { Groaning, whining, whimpering } \\
\text { Shouting }\end{array}$ & $\begin{array}{l}0 \\
1 \\
2\end{array}$ \\
\hline $\begin{array}{r}\text { observations at } \\
\text { defined time intervals } \\
\text { have greater } \\
\text { information value than }\end{array}$ & Facial expression & $\begin{array}{l}\text { Relaxed, smiling } \\
\text { Mouth distorted } \\
\text { Mouth and eyes grimacing }\end{array}$ & $\begin{array}{l}0 \\
1 \\
2\end{array}$ \\
\hline $\begin{array}{c}\text { a single observation. } \\
\text { A check on the degree } \\
\text { of alertness is part of } \\
\text { each observation. }\end{array}$ & Trunk posture & $\begin{array}{l}\text { Neutral } \\
\text { Unsettled } \\
\text { Rearing up, arching }\end{array}$ & $\begin{array}{l}0 \\
1 \\
2\end{array}$ \\
\hline $\begin{array}{l}\text { A sleeping child has } \\
\text { no acute analgesic } \\
\text { therapy requirement. } \\
\text { Analgesic therapy }\end{array}$ & Leg posture & $\begin{array}{l}\text { Neutral } \\
\text { Struggling, kicking } \\
\text { Drawn up to body }\end{array}$ & $\begin{array}{l}0 \\
1 \\
2\end{array}$ \\
\hline $\begin{array}{l}\text { requirement begins } \\
\text { with four points. Its } \\
\text { urgency increases with } \\
\text { rising points score }\end{array}$ & Motor restlessness & $\begin{array}{l}\text { Not present } \\
\text { Moderate } \\
\text { Restless }\end{array}$ & $\begin{array}{l}0 \\
1 \\
2\end{array}$ \\
\hline & Points total: & & \\
\hline
\end{tabular}

${ }^{\star} 1 \mathrm{KUSS}$, Kindliche Unbehagen- und Schmerz-Skala; The scale is suitable for newborns and young children up to the end of the fourth year of age. Modified from (5).

24 hours. Regardless of whether it is decided to treat the child with antibiotics, additional analgesic therapy, for example with ibuprofen, should be initiated for a variable period of one to seven days (recommendation level A) (2). Severe acute pain is also experienced postoperatively. Compared to adults, pediatric patients receive fewer and/or incorrectly dosed analgesics in daily routine (e1). Severe pain experiences in childhood can - even if they cannot subsequently be consciously recalled - lead via the development of a pain memory to unusual sensory processing of pain and altered behavioral patterns persisting well beyond convalescence. If adequate pain prevention is neglected in a single painful intervention, this results in higher analgesic requirements, increased stress and pain as well as a greater proportion of failed analgesia and sedation in subsequent interventions (2).

\section{Chronic pain}

Chronic and recurrent pain is a frequent phenomenon during childhood (1, e1, e2) and may be associated with increased anxiety and depression, a restricted level of physical/psychosocial functioning, and frequent school absenteeism (e6). The parents of the affected children are frequently under severe emotional stress and have a tendency to exhibit pain exacerbating reactions (e7, e8).
Persisting pain during childhood predisposes towards the development of chronic pain in adulthood (3, 4, e9-e13).

\section{Pain assessment}

Pain is a subjective phenomenon. Verbal self-reporting is therefore the gold standard for qualitative and quantitative pain measurement both for children of school age and adults (recommendation level B) (5, e14). For pain perception see ebox 1 .

Newborns, infants and young children: The Childhood Discomfort and Pain Scale (KUSS, Kindliche Unbehagen- und Schmerz-Skala) is suitable for assessing postoperative pain in non-mechanically ventilated newborns up to the end of the fourth year (table 1) (6).

Preschool and school children: The KUSS can be used in children without knowledge of German, whose general or linguistic development is delayed, or who are situationally impaired by anxiety. Depending on the developmental status and previous experience, a face pain scale for self rating should be used in children from five years of age (figure). Of all the face pain scales, preference should be given to those which are free of emotional content. A face with tears running down can have different meanings; younger children may possibly use this variant to express high pain intensity, while older children do not wish to cry despite having pain whether because of cultural or family values - and therefore report falsely low values. A laughing face at the beginning of the scale may possibly result in a false high pain score because sick children even without pain rarely see themselves as "happily" laughing. The "Faces Pain Scale-Revised" (7) shows good psychometric characteristics and is most suitable for this age group $(8, \mathrm{e} 15)$.

Chronic pain: Questionnaires record further pain dimensions such as pain quality, concomitant symptoms, pain-inducing/exacerbating conditions, pain related impairment, emotional distress, quality of life, pain related coping, and self rating of therapy related improvement. Pain relevant factors in the social environment (family, kindergarten, school) are components of the interview guide. For younger children or when there is a wish for additional information, the parent's reported information is also included. For chronic pain, it is indispensable under diagnostic and therapeutic aspects to keep a pain diary designed suitably for children (e14).

\section{Pain experience}

The experience of extreme pain in childhood and adolescence can result in the development of a pain memory.

\section{Consequences of pain experience}

Chronic pain in children causes frequent school absenteeism and if left untreated predisposes towards chronic pain in adulthood. 


\section{Postoperative pain therapy in children and adolescents}

Younger children perceive the same injuries as more painful than older children (e16). Multimodal preventive and therapeutic concepts for perioperative pain integrate psychological, pharmacological, and physical techniques (immobilization etc.). The best basis for ensuring effectiveness of pain therapy is good psychological preparation by provision of age-appropriate information.

\section{Principles of non-pharmacological treatment}

The purpose of psychological interventions is to prevent children developing anxieties and to beneficially influence pain experience through cognitive and emotional processes. Several methods are indispensable for this purpose:

- Since situational factors influence children's pain experience to a particular degree, optimal background conditions such as age-appropriate briefing, procedures without long waiting times, and child-appropriate room design are important.

- To reduce or prevent anxieties and negative emotional stress factors, cognitive and behavioral therapeutic methods such as age-appropriate education, breathing exercises, role playing, external attention directing or imaginative techniques adjusted to the individual situation - are to be included (5, e17) (recommendation level A for individual psychological interventions for painful procedures).

\section{Principles of pharmacological treatment}

Therapeutic administration of placebos in response to children's acute expressions of pain are not generally productive and ethically highly questionable (see ebox 2). In non-sedated children, intramuscular and subcutaneous injections are to be strictly avoided. Depending on age and culture, rectal administration is often unwelcome. Plasma level concentrations and onset of action - of paracetamol for example - are unpredictable after rectal administration. The absorption of orally administered medications may be delayed in the immediate postoperative period. The intravenous administration of analgesics allows rapid titration according to pain in the recovery room. In the immediate postoperative period on the ward, analgesics should be given according to a fixed time schedule ("by the clock") and additionally on demand - for a variable period depending on the scale of the operation. Analgesics

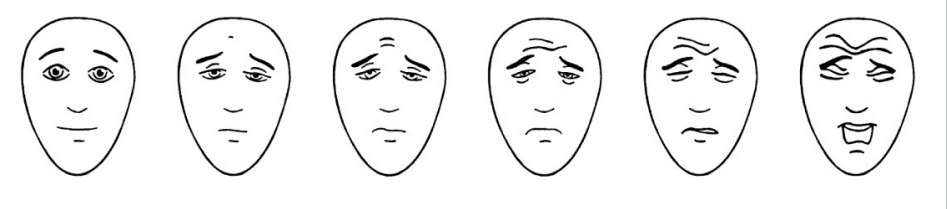

Figure: Faces Pain Scale for children aged about 5 years onwards (7) Instructions for taking a medical history of the child's pain situation: "These faces show how much something can hurt. This face (point to left-most face) shows no pain. The faces show more and more pain (point to each from left to right) up to this one (point to right-most face) - it shows very much pain. Point to the face that shows how much you hurt (right now)." To convert to a points system and document in the patient curve, score the chosen face 0,2 , $4,6,8$ or 10 , counting left to right. From a score of four onwards there is an analgesic requirement for acute pain. (www. painsourcebook.ca). Figure with kind permission of ISAP

should then be administered according to demand based on the pain score.

Monitoring: Standardized monitoring and documentation protocols are recommended for this purpose. After titration to the required dose, a pain measurement should be performed every two to four hours (at rest and during exercise) with continuous infusion of analgesics.

\section{Analgesics}

Modern evidence-based perioperative analgesic regimens are stratified according to the scale, localization, and extent of the operation. They often comprise a combination of regional anesthesiological interventions and systemically acting analgesics (balanced procedure, recommendation level A to $\mathrm{C}$ depending on the operation studied). The evidence situation is essentially unsatisfactory in this indication.

\section{Non-opioids}

The choice of non-opioids is based on the pathophysiology of the pain and on contraindications. For inflammatory pain, non-steroidal anti-inflammatory drugs (NSAIDs) are used, for spasmodic abdominal pain metamizole and if there is an increased hemorrhagic risk, paracetamol or metamizole. A comparison of the two most commonly used non-opioids paracetamol and ibuprofen is provided in table 2.

Paracetamol: Paracetamol (PCM) has no clinically relevant inhibitory effect on platelet aggregation. It has no anti-inflammatory component. The adverse effects

\section{KUSS scale}

Acute pain in newborns, infants, and young children is assessed with the KUSS scale. Preschool and school children can report their pain themselves.

\section{Pain prevention strategies}

Non-pharmacological pain prevention strategies are important because anxiety can intensify pain. 
TABLE 2

Comparison of advantages and disadvantages of ibuprofen and paracetamol in pain therapy*1

\begin{tabular}{|c|c|c|}
\hline & Ibuprofen & Paracetamol \\
\hline \multicolumn{3}{|l|}{ Advantages } \\
\hline & $\begin{array}{l}\text { Potent analgesic effect } \\
\text { Wide therapeutic range } \\
\text { Low toxicity on overdose } \\
\text { Palatable syrups } \\
\text { Better tolerability in children } \\
<2 \text { years with history } \\
\text { of obstructive bronchitis } \\
\text { Dose certainty } \\
\text { ( } 3 \times 10 \mathrm{mg} / \mathrm{kg} / \mathrm{BW} / \mathrm{day}) \\
\text { Long duration of action }(8 \mathrm{~h})\end{array}$ & $\begin{array}{l}\text { Rectal administration form also } \\
\text { available for young children } \\
\text { Approved for infants } \\
<6 \text { months } \\
\text { No antiplatelet effect } \\
\text { Intravenous formulation available }\end{array}$ \\
\hline \multicolumn{3}{|l|}{ Disadvantages } \\
\hline & $\begin{array}{l}\text { Only approved from } \\
\text { age } 6 \text { months } \\
\text { Risk of acute renal failure } \\
\text { if pre-existing relevant } \\
\text { dehydration }\end{array}$ & $\begin{array}{l}\text { Dose uncertainty } \\
\text { - Narrow therapeutic range } \\
\text { - Extremely high toxicity } \\
\text { on overdose } \\
\text { - Weak analgesic potency } \\
\\
\text { Relatively unpalatable } \\
\text { oral formulation }\end{array}$ \\
\hline
\end{tabular}

${ }^{*} 5,15,16,25$, e19, e48-e53; BW, body weight

typical of non-steroidal anti-inflammatory drugs, such as gastrointestinal mucosal injury, are absent. Paracetamol is hepatically glucuronidated and/or sulfated. Overdose results in formation of the highly toxic $\mathrm{N}$-acetyl-pbenzoquinone imine (NAPQI). Genetic changes (polymorphisms of CYP2E1; autosomal recessive inherited deficit of glutathione synthesis) may make affected children more susceptible to the paracetamol associated hepatotoxicity.

PCM is approved for use from birth onwards. The analgesic potency of paracetamol is rated by many authors as lower than that of ibuprofen or other NSAIDs (5, e18). Postoperatively, paracetamol monotherapy is only weakly effective (e19). Dose recommendations for paracetamol are given in table 3.
Non-steroidal anti-inflammatory drugs (NSAIDs): The NSAID most widely used in pediatrics is ibuprofen (table 4). Like all non-selective NSAIDs, it inhibits cyclooxygenase (COX) type I and II and secondarily also platelet aggregation. For interventions with an increased hemorrhagic risk (tonsillectomy, large wound areas etc.) and in patients with hemorrhagic tendency a careful risk assessment is required. The influence of COX I and II inhibitors on the incidence of relevant bleeding after tonsillectomy has not yet been conclusively determined: a Cochrane analysis concludes that the risk of relevant post-tonsillectomy bleeding is not increased by NSAIDs (9, e20-e22). Children rarely develop gastrointestinal mucosal injury and nephrotoxicity after short-term ibuprofen therapy (less than seven days). These adverse effects do not occur more often than with paracetamol. Individual cases of acute renal failure have been reported when dehydrated children received NSAIDs. In children with mild bronchial asthma, the risk of an allergic reaction to NSAIDs is classified as low. Ibuprofen is only approved for use in children older than six months since in younger infants the risk of reduced cerebral or renal blood flow may be increased.

Metamizole: Because of its spasmolytic properties metamizole is particularly suitable for visceral pain or colicky pain. Caution is advised in patients with a history of asthma or allergies and when the cardiovascular situation is unstable. During intravenous therapy, a considerable fall in blood pressure and even shock can occur due to hypersensitivity reactions or allergies.

Metamizole should only be administered as a short infusion and always with close monitoring of blood pressure values. More useful than repeated short infusions is a long-term infusion with a dosage of 2.5 to $3.0 \mathrm{mg} / \mathrm{kg} / \mathrm{h}$. Metamizole is - depending on the route of administration and the product - approved for use from the age of three months onwards. A risk assessment for agranulocytosis in children receiving metamizole therapy is not possible at present - only one such case has been reported to date (10)

\section{Opioids}

Newborns, infants, and children with pre-existing cerebral impairment react with particular sensitivity to opioids, which therefore have to be initiated at low doses and titrated upwards slowly until maximal control of the symptoms amenable to pharmacotherapy is achieved. Besides respiratory depression and sedation,

\section{Paracetamol}

The low analgesic potency, variable absorption after rectal administration, and the narrow therapeutic range should be considered when using paracetamol.

\section{Non-steroidal anti-inflammatory drugs}

Gastrointestinal mucosal injury and nephrotoxicity rarely occur in children during short-term treatment with ibuprofen. 


\section{TABLE 3}

\section{Recommended dosages for paracetamol*1}

\begin{tabular}{|c|c|c|c|c|}
\hline & $\begin{array}{l}\text { Single initial dose } \\
\text { at start of therapy } \\
(\mathrm{mg} / \mathrm{kg})\end{array}$ & $\begin{array}{l}\text { Follow-on dose } \\
(\mathrm{mg} / \mathrm{kg})\end{array}$ & $\begin{array}{l}\text { Dose interval } \\
\text { (h) }\end{array}$ & $\begin{array}{l}\text { Max. daily dose } \\
\text { (mg/kg/day) }\end{array}$ \\
\hline \multicolumn{5}{|l|}{ Rectal } \\
\hline Premature infants $28^{\text {th }}-30^{\text {th }} \mathrm{GW}$ & 20 & 15 & 12 & 35 \\
\hline Premature infants $31^{\text {st }}-38^{\text {th }} \mathrm{GW}$ & 20 & 15 & 12 & 45 \\
\hline $\begin{array}{l}\text { Newborns and infants } \\
\text { up to age } 6 \text { months }\end{array}$ & 30 & 15 & 8 & 60 \\
\hline Infants after $6^{\text {th }}$ month & $35-45$ & $15-20$ & $6-8$ & 60 \\
\hline Young children $>1$ year & $35-45$ & $15-20$ & $(4-) 6$ & 75 \\
\hline Children $>6$ years & $35-45$ & $15-20$ & $(4-) 6$ & $\begin{array}{l}90 \\
\text { Absolute maximum } \\
4000 \mathrm{mg} / \text { day }\end{array}$ \\
\hline \multicolumn{5}{|l|}{ Oral } \\
\hline $\begin{array}{l}\text { Newborns and infants } \\
\text { up to age } 6 \text { month }\end{array}$ & 20 & 20 & 8 & 60 \\
\hline Infants after 6th month & 30 & $10-20$ & $(4-) 6$ & 60 \\
\hline Young children $>1$ year & 30 & 15 & $(4-) 6$ & 75 \\
\hline Children $>6$ years & 30 & 15 & $(4-) 6$ & $\begin{array}{l}90 \\
\text { Absolute maximum } \\
4000 \mathrm{mg} / \text { day }\end{array}$ \\
\hline \multicolumn{5}{|l|}{ Intravenous } \\
\hline All age groups & 15 & 15 & 6 & $\begin{array}{l}60 \\
\text { Absolute maximum } \\
4000 \mathrm{mg} / \text { day }\end{array}$ \\
\hline
\end{tabular}

After rectal administration the peak plasma level is only reached after 2 to 3 hours because of slow and variable absorption (e18). For oral or rectal administration a saturation dose should be given on starting treatment. For intravenous therapy the saturation dose is not required. Maximal analgesia is achieved 1 to 2 hours after rapid (within $10 \mathrm{~min}$ ) intravenous administration (e18). Because of the narrow therapeutic range the age adapted maximum daily dose should not be exceeded and not administered for longer than 48 hours; ${ }^{* 1}$ modified from (11, e19); GW, gestation week

\section{TABLE 4}

Recommended dosages for several selected NSAIDs and metamizole*1

\begin{tabular}{|l|l|l|l|l|}
\hline $\begin{array}{l}\text { Substance } \\
\text { Ibuprofen }\end{array}$ & Dosage route & Single dose $(\mathrm{mg} / \mathrm{kg})$ & Dose interval (h) & Max. daily dose (mg/kg/day) \\
\hline Diclofenac & Oral/rectal & $10-15$ & 8 & $\begin{array}{l}30-40 \\
\text { Absolute: } 2400 \mathrm{mg} / \mathrm{day}\end{array}$ \\
\hline Metamizole & $\begin{array}{l}\text { Oral//rectal } \\
\text { Oral/rectal/ } \\
\text { short i.v. infusion/ } \\
\text { slow drip infusion }\end{array}$ & $1-2$ & $8-12$ & $\begin{array}{l}3 \\
\text { Absolute: } 150 \mathrm{mg} / \text { day }\end{array}$ \\
\hline
\end{tabular}

\section{Choice of non-opioid}

The choice of the non-opioid is based on the pathophysiology of the pain and the possible contraindications.

\section{Indications of non-opioids}

- Inflammatory pain $\Rightarrow$ NSAIDs

- Spasmodic (abdominal) pain $\Rightarrow$ metamizole

- Increased hemorrhagic risk $\Rightarrow$ PCM or metamizole 
the same adverse effects are essentially seen in children as in adults (nausea, vomiting, constipation, pruritus, urinary retention, lowered seizure threshold). The risk of dependence is to be classified as low. An extensive literature search failed to disclose a single documented case. As opioids for moderate to severe pain, tramadol and tilidine, for severe to very severe pain especially morphine and, if this is poorly tolerated by certain individuals, buprenorphine, hydromorphone, and oxycodone are used. Despite scant scientific evidence, piritramide is widely used in Germany (Recommendation level for postoperative use of opioids [also as patient-controlled analgesia, PCA] depending on the operation: A to C) (5).

Tramadol: Tramadol has not only an opioid receptor mediated action but also serotonergic and adrenergic mechanisms of action (11). After a saturation dose, a continuous long-term infusion is more suitable because of its better tolerability. Especially the combination with metamizole has proved successful particularly for visceral pain. Tramadol is not subject to the German Federal Narcotics Act.

Tilidine/naloxone: Tilidine/naloxone can be used orally in older children in the later postoperative course. Tilidine is not subject to the provisions of the German Federal Narcotics Act.

Morphine: Morphine is the opioid of choice for pediatric use. Starting doses are listed in table 5. The safety and efficacy of continuous intravenous administration of opioids for pain management are well established for all age groups (e1).

Morphine PCA: Patient-controlled analgesia (PCA) can be used in children aged six years or more $(5, \mathrm{e} 14)$. Postoperatively, a basic infusion of $4 \mu \mathrm{g} / \mathrm{kg} / \mathrm{h}$ morphine is not associated with an increased rate of adverse effects (e23). Pediatric opioid PCA requires special logistics and regular monitoring of vital signs. Loading doses are shown in table 5, the lockout time - loading dose demand does not result in a loading dose but is recorded by the PCA pump - is usually ten minutes.

Piritramide: Because of its acidic $\mathrm{pH}$, piritramide should not be given together with other drugs through the same intravenous line. The dosage corresponds to that of morphine (table 5).
Pethidine: The use of pethidine is no longer recommended because of its long half-life and the seizure threshold lowering metabolite norpethidine. Norpethidine can cumulate during prolonged pethidine use and postoperatively (11, e24, e25).

\section{Regional anesthesia and analgesia}

In children, regional anesthesia should be carried out under deep sedation or general anesthesia (table 6). The Pediatric Anesthesia Working Group of the German Society of Anesthesiology draws attention to the fact that routine clotting analyses are not required in healthy children before applying regional anesthesia. Ropivacaine appears to be the local anesthetic of first choice for epidural/caudal analgesia because of its low cardiotoxicity, low incidence of motor blocks, and favorable pharmacokinetics on continuous administration (5, e26). In children, respiratory and sedation monitoring should be practiced for at least $24 \mathrm{~h}$ after epidural opioid administration.

\section{Chronic and recurrent pain}

Headache is one of the commonest pediatric health problems (12, e2). In Germany an estimated 1000000 school days are missed every year because of headache.

Migraine: $5 \%$ to $10 \%$ of all 7 - to 15 -year-olds suffer from migraine (in most cases without aura). In the last 20 years the prevalence of migraine among 7-year-olds has risen from $1.9 \%$ to $5.2 \%$ (e27). The diagnostic criteria of the International Headache Society (IHS) define migraine without aura as follows (13).

- At least five attacks fulfil the following criteria

- Duration of attack $4 \mathrm{~h}$ (children $1 \mathrm{~h}$ ) to $72 \mathrm{~h}$

- Headache fulfils at least two of the following criteria

- Unilateral location (children also: bilateral frontal/ temporal)

- Pulsating

- Moderate to severe pain intensity

- Exacerbation on physical activity

- Headache is accompanied by at least one of the following symptoms

- Nausea and/or vomiting

- Photophobia and phonophobia.

Tension-type headache: Up to $25 \%$ of all children aged 7 to 15 years complain of episodic tension-type headache. In contrast to migraine, the pain attack may last from 30 minutes to 7 days and is of lower intensity

\section{Tramadol}

Tramadol is very well tolerated as a long-term infusion in pediatric use.

\section{Morphine}

Morphine is the most thoroughly studied potent opioid in pediatrics; and can be safely used at any age (subject to compliance with age-appropriate weight based dosage and monitoring standards). 


\section{TABLE 5}

\section{Opioid starting doses for opioid-naive children and adolescents}

\begin{tabular}{|c|c|c|c|}
\hline Dosage route & \multicolumn{3}{|c|}{$\begin{array}{l}\text { Usual starting dose for children of body weight }>10 \mathrm{~kg} \text { and } \\
\text { age }>6 \text { months }\end{array}$} \\
\hline \multicolumn{4}{|c|}{ Opioids for severe and very severe pain (WHO III) } \\
\hline \multicolumn{4}{|l|}{ Buprenorphine } \\
\hline \multirow[t]{3}{*}{ Intravenous } & Loading dose & $0.003 \mathrm{mg} / \mathrm{kg}$ & (max. $0.15 \mathrm{mg}$ ) every $6 \mathrm{~h}$ \\
\hline & PCA loading dose & $0.001 \mathrm{mg} / \mathrm{kg}$ & (max. $0.06 \mathrm{mg})$ \\
\hline & SDI & $0.0005 \mathrm{mg} / \mathrm{kg} / \mathrm{h}$ & (max. $0.03 \mathrm{mg} / \mathrm{h}$ ) \\
\hline \multicolumn{2}{|l|}{ Sublingual } & $0.004 \mathrm{mg} / \mathrm{kg}$ & (max. $0.2 \mathrm{mg}$ ) every $8 \mathrm{~h}$ \\
\hline \multicolumn{4}{|c|}{ Hydromorphone } \\
\hline \multirow[t]{3}{*}{ Intravenous } & Loading dose & $0.01 \mathrm{mg} / \mathrm{kg}$ & (max. $0.5 \mathrm{mg}$ ) every $3 \mathrm{~h}$ \\
\hline & PCA loading dose & $0.004 \mathrm{mg} / \mathrm{kg}$ & (max. $0.2 \mathrm{mg}$ ) \\
\hline & SDI & $0.005 \mathrm{mg} / \mathrm{kg} / \mathrm{h}$ & (max. $0.2 \mathrm{mg} / \mathrm{h}$ ) \\
\hline \multirow[t]{2}{*}{ Oral } & Immediate release & $0.03 \mathrm{mg} / \mathrm{kg}$ & (max. $1.3 \mathrm{mg}$ ) every $4 \mathrm{~h}$ \\
\hline & Sustained release & $0.06 \mathrm{mg} / \mathrm{kg}$ & (max. $4 \mathrm{mg}$ ) every $8 \mathrm{~h}$ \\
\hline \multicolumn{4}{|l|}{ Morphine ${ }^{* 1}$} \\
\hline \multirow{3}{*}{$\begin{array}{l}\text { Intravenous/ } \\
\text { subcutaneous }\end{array}$} & Loading dose & $0.05 \mathrm{mg} / \mathrm{kg}$ & (max. $3 \mathrm{mg}$ ) every $3 \mathrm{~h}$ \\
\hline & PCA loading dose & $0.02 \mathrm{mg} / \mathrm{kg}$ & (max. $2 \mathrm{mg}$ ) \\
\hline & SDI & $0.02 \mathrm{mg} / \mathrm{kg} / \mathrm{h}$ & $(\max .0 .5 \mathrm{mg} / \mathrm{h})$ \\
\hline \multirow[t]{2}{*}{ Oral } & Immediate release & $0.2 \mathrm{mg} / \mathrm{kg}$ & (max. $5 \mathrm{mg}$ ) every $4 \mathrm{~h}$ \\
\hline & Sustained release & $0.4 \mathrm{mg} / \mathrm{kg}$ & (max. $10 \mathrm{mg}$ ) every $8 \mathrm{~h}$ \\
\hline \multicolumn{4}{|l|}{ Oxycodone } \\
\hline \multirow{3}{*}{$\begin{array}{l}\text { Intravenous/ } \\
\text { subcutaneous }\end{array}$} & Loading dose & $0.04 \mathrm{mg} / \mathrm{kg}$ & (max. $2 \mathrm{mg}$ ) every $4 \mathrm{~h}$ \\
\hline & PCA loading dose & $0.02 \mathrm{mg} / \mathrm{kg}$ & (max. $1.3 \mathrm{mg})$ \\
\hline & SDI & $0.02 \mathrm{mg} / \mathrm{kg} / \mathrm{h}$ & $(\max .0 .5 \mathrm{mg} / \mathrm{h})$ \\
\hline \multirow[t]{2}{*}{ Oral } & Immediate release & $0.1 \mathrm{mg} / \mathrm{kg}$ & (max. $5 \mathrm{mg}$ ) every $4 \mathrm{~h}$ \\
\hline & Sustained release & $0.2 \mathrm{mg} / \mathrm{kg}$ & (max. $10 \mathrm{mg}$ ) every $8 \mathrm{~h}$ \\
\hline \multicolumn{4}{|c|}{ Opioids for moderate and severe pain (a dose of $10 \mathrm{mg} / \mathrm{kg} /$ day or $600 \mathrm{mg} /$ day should not be exceeded) } \\
\hline \multicolumn{4}{|l|}{ Tramadol } \\
\hline \multirow[t]{3}{*}{ Intravenous } & Loading dose & $1 \mathrm{mg} / \mathrm{kg}$ & (max. $50 \mathrm{mg}$ ) every $4 \mathrm{~h}$ \\
\hline & PCA loading dose & $0.3 \mathrm{mg} / \mathrm{kg}$ & (max. $10 \mathrm{mg})$ \\
\hline & SDI & $0.3 \mathrm{mg} / \mathrm{kg} / \mathrm{h}$ & (max. $10 \mathrm{mg} / \mathrm{h})$ \\
\hline \multirow[t]{2}{*}{ Oral } & Immediate release & $1 \mathrm{mg} / \mathrm{kg}$ & (max. $50 \mathrm{mg}$ ) every $4 \mathrm{~h}$ \\
\hline & Sustained release & $2 \mathrm{mg} / \mathrm{kg}$ & (max. $100 \mathrm{mg}$ ) every $8 \mathrm{~h}$ \\
\hline \multicolumn{4}{|c|}{ Tilidine/Naloxone } \\
\hline \multirow[t]{2}{*}{ Oral } & Immediate release & $1 \mathrm{mg} / \mathrm{kg}$ & (max. $50 \mathrm{mg}$ ) every $4 \mathrm{~h}$ \\
\hline & Sustained release & $2 \mathrm{mg} / \mathrm{kg}$ & (max. $100 \mathrm{mg}$ ) every $8 \mathrm{~h}$ \\
\hline
\end{tabular}

For infants $<6$ months and children of body weight $<10 \mathrm{~kg}$ or in children with cerebral impairment, the starting doses should be reduced by two-thirds to one third of the dose shown here. Follow-on doses should always be titrated slowly depending on response. Max., maximum single dose at the start of opioid therapy in older children, adolescents, and young adults; SDI, slow drip infusion; for SDI the maximum dose per hour is stated; ${ }^{* 1}$ parenteral piritramide is dosed like morphine. Modified from Cancer Pain Relief and

Palliative Care in Children (WHO 1998 [11])

\section{Use of opioids}

Opioids are always titrated according to effect. The starting dose is based on the child's age and comorbidities.

\section{Establishment of opioids}

Safety and efficacy of continuous intravenous administration of opioids for pain management are well established for all age groups. 
TABLE 6

Regional anesthesia and analgesia techniques according to surgical intervention

\begin{tabular}{l|l|l}
$\begin{array}{l}\text { Operation } \\
\text { Urogenital }\end{array}$ & Regional anesthetic technique & Evidence level*1 \\
\hline $\begin{array}{l}\text { Circumcision } \\
\text { Hypospadias correction }\end{array}$ & Caudal anesthesia or subpubic penile block & A (very high) \\
\hline Orchidopexy & Caudal anesthesia & A (very high) \\
\hline Herniotomy (open) & Wound infiltration, ilioinguinal block; caudal anesthesia & A (very high) \\
\hline Abdominal & PDA & A (very high) \\
\hline Extensive abdominal surgery & Wound infiltration additionally to other analgesic measures & \\
\hline Appendectomy (open) & PDA & B (high) \\
\hline Fundoplication (open) & D (low) \\
\hline $\begin{array}{l}\text { Orthopedic } \\
\text { Lower extremity }\end{array}$ & PCEA (low) \\
\hline Upper extremity (hand, forearm) & Brachial plexus block & C (medium) \\
\hline Spine & PDA, poss. with two catheters & D (low) \\
\hline $\begin{array}{l}\text { Various } \\
\text { Thoracotomy }\end{array}$ & PDA & C (medium) \\
\hline
\end{tabular}

${ }^{\star}$ 1 Detailed definition of Evidence level on the internet, evidence levels: A (very high; high quality meta-analyses, randomized controlled trials [RCTs]) B (high; systematic review articles); C (medium; good case control or cohort studies); D (low, case series). PDA, peridural anesthesia and postoperative analgesia; PCEA, patient controlled epidural analgesia. Modified from (7)

(13). $5 \%$ of the children complain of nausea, $15 \%$ of photophobia/phonophobia respectively during the headache phase (e28, e29).

\section{Diagnostic procedures for headache}

Recurrent headache in childhood can usually be diagnosed on the basis of the medical history and physical examination (14). Electroencephalography (EEG) is only recommended if associated symptoms suggest the presence of a cerebral convulsive disorder (14). A cranial MRI (magnetic resonance imaging) scan is only indicated in exceptional cases (ebox 3 ).

Pharmacological therapeutic approaches for acute migraine attacks: Treatment of migraine attacks is stratified according to severity, duration, and accompanying symptoms (12). Single-agent preparations are to be preferred and administered in sufficiently high dosages. Ibuprofen is superior to paracetamol; a direct comparison shows that complete pain relief after two hours is achieved twice as frequently with ibuprofen (15). For attacks of headache that are already initially very severe, rapidly progressive, or accompanied by numerous other symptoms and if the primary ibuprofen therapy is ineffective, sumatriptan nasal spray should be used, which is approved in Germany for use in children aged 12 years or more (dose: $10 \mathrm{mg}$ intranasal) (8) (recommendation level A, [8, 12, 16, e30-e33]). Acetylsalicylic acid should only be used from age 12 years onwards because of the risk of Reye's syndrome (e34).

Migraine prophylaxis: The efficacy of multimodal outpatient treatment programs (including elements from cognitive behavioral therapy, relaxation techniques, hypnosis, biofeedback, and endurance training) has been convincingly demonstrated (recommendation level A) $(1,17,18)$.

Purely clinical experience shows that a regular life style with sufficient sleep, a balanced diet and adequate fluid intake is helpful. Pharmacological prophylaxis in

\section{Regional anesthesia}

Regional anesthesia should only be performed under deep sedation or general anesthesia.

\section{Children and headache}

Headache in childhood is very common. Migraine attacks are often shorter than in adults and may often be bilateral. The differential diagnosis of childhood headache should be made by a pediatrician. 
childhood should only be employed if attack therapy is inadequate and the non-pharmacological prophylactic measures fail (12). Migraine prophylaxis is performed for a period of three to six months keeping a migraine diary and is then interrupted to assess the spontaneous course. The medications are generally titrated upwards from an initial low level and finally tapered out. The most commonly used substances are the beta blocker metoprolol and the calcium channel blocker flunarizine (no beta blockers in patients with asthma) and the anticonvulsant topiramate (recommendation level D, because of conflicting study results [12, 19, e35-e41]).

Treatment options in tension-type headache: In most cases this headache can be treated using nonpharmacological strategies which have to be learned by the child in group or in one-to-one sessions, such as muscle relaxation by the Jacobson method as well as cognitive-behavioral strategies and biofeedback. TENS (transcutaneous electrical nerve stimulation) has proved helpful in open-label studies.

\section{Chronic abdominal pain}

The prevalence of chronic abdominal pain among children of school age is $10 \%$ to $25 \%$ (e42). Apley defines typical chronically recurrent abdominal pain as abdominal pain that occurs episodically at least once a month for at least three months in succession and impairs the child's normal activities (20). At present, chronic abdominal pain is classified according to the Rome III criteria (21) (ebox 4). In more than half of the cases the functional abdominal pain is already primarily associated with other forms of pain such as headache and chest pain.

Children with functional abdominal pain show characteristic features (e42):

- Periumbilical $(45 \%)$ or epigastric pain $(40 \%)$ lasting for less than one hour in two thirds of the children and almost always for less than three hours

- Child and parents can almost never name measures that shorten the pain event

- Pain is frequently associated with autonomic nervous symptoms such as pallor and nausea

- Physical examination reveals no abnormalities.

Caution is advised if one of the warning signs mentioned in the box occur (box).

Somatic, mental, and social "abnormalities": Many of the children affected show "abnormalities" such as disorders of gastrointestinal motility, carbo- hydrate malabsorption or positive Helicobacter pylori tests. The presence of positive organic findings, however, has no influence on the long-term course (22). According to the ESPGHAN (European Society for Pediatric Gastroenterology, Hepatology, and Nutrition) Consensus Statement, there is no validated relationship between the Helicobacter infection and chronic recurrent abdominal pain (22). Children with abdominal pain and nonulcerative gastritis do not benefit symptomatically from HP eradication. Many psychosocial "abnormalities" have been proclaimed for these children and their families. The study results are contradictory, especially in cases where not healthy but chronically ill children and their families were used as reference group.

\section{Bio-psycho-social model}

After excluding other diseases by means of medical history and physical examination, the pediatrician can continue searching for "the" cause or interpret the functional pain within the context of a bio-psycho-social model (23, e43): a child's vulnerability in terms of functional abdominal pain is an interplay between organic dysfunction (in these cases especially of the gastrointestinal tract) and psychological factors. Once functional abdominal pain has developed, the recurrent pain experience increases the child's vulnerability, and this all the more, the more clearly the pain is perceived and intensified by the environment. Stressors can be psychosocial or biological in nature (e.g. lactose loading).

\section{Treatment}

In several studies on the long term course over 5 to 30 years, the children who formerly suffered functional abdominal symptoms were now suffering considerably more frequently from chronic abdominal pain, other somatic symptoms, and psychosocial disorders (e44). No significantly positive therapeutic results were obtained for functional abdominal symptoms on introducing lactose-free diet or increasing nutritional dietary fiber (24). The course of functional abdominal symptoms can be favorably influenced by strategies such as comprehensive education about the maintenance of chronic pain and learning appropriate pain related coping strategies. Cognitive behavioral therapy combined with training measures for parents are also promising (recommendation level A) (1, e44). Other forms of chronic abdominal pain also benefit from pharmacological therapeutic approaches such as attack therapy with ibuprofen for abdominal migraine.
Medication with acetylsalycilic acid (ASA)

Due to the risk of Reye's syndrome, ASA should generally only be used from age 12 years onwards.

\section{Treatment of migraine attacks}

The treatment of migraine attacks is stratified according to pain and course. Non-pharmacological strategies for migraine prophylaxis are very well validated and effective over years. Pharmacological prophylaxis of migraine plays a secondary role. 
BOX

\section{Alarm signs for the presence of another disease than abdominal pain are:}

- Persisting pain in the right upper or right lower quadrant

- Pain that rouses the child from sleep

- Pain duration $>12 \mathrm{~h}$

- Distinctly periodic course

- Nocturnal diarrhea

- Persisting vomiting

- Dysphagia

- Gastrointestinal blood loss

- Perianal diseases

- Unwanted weight loss

- Slowing of longitudinal growth

- Delayed puberty

- Fever of indeterminable etiology

- Arthritis

- Family history of inflammatory bowel diseases, celiac disease or peptic ulceration
Manuscript received on 20 November 2007, revised version accepted on 11 June 2008.

Translated from the original German by mt-g

\section{REFERENCES}

1. Eccleston C, Morley S, Williams AC, Yorke L, Mastroyannopoulou K: Systematic review of randomised controlled trials of psychological therapy for chronic pain in children and adolescents, with a subset of meta-analysis of pain relief. Pain 2002; 99: 157-65.

2. American Academy of Pediatrics Subcommittee on Management of Acute Otitis Media: Diagnosis and management of acute otitis media Pediatrics 2004; 113(5): 1451-65.

3. Christensen FM, Mortensen 0: Long-term prognosis in children with recurrent abdominal pain. Arch Dis Child 1975; 50: 110-4.

4. Walker LS, Garber J. Van Slyke DA, Greene JW: Long-term health out comes in patients with recurrent abdominal pain. J Pediatr Psychol 1995; 20: 233-45.

5. Association of Paediatrics Anaesthetists. Good Practise in Postoperative and Procedural Pain. www.apagbi.org.uk. 2007

6. Büttner W, Finke W: Analysis of behavioural and physiological parameters for the assessment of postoperative analgesic demand in newborns, infants and young children: a comprehensive report on seven consecutive studies. Paediatr Anaesth 2000; 10: 303-18.

7. Hicks CL, von Baeyer CL, Spafford PA, van Korlaar I, Goodenough B: The Faces Pain Scale - Revised: Toward a common metric in pediatric pain measurement. Pain 2001; 93:173-83.

8. von Baeyer CL: Children's self-report of pain intensity: Scale selection, limitations and interpretations. Pain Res Manag 2006; 11:157-62.

9. Cardwell M, Siviter G, Smith A: Non-steroidal anti-inflammatory drugs and perioperative bleeding in paediatric tonsillectomy (Review). Cochrane Database Syst Rev 2005; 2005: Art. No.: CD003591DOl:10.1002/14651858.CD003591.pub2

10. Meyer O, Geadicke G, Salama A: Demonstration of drug-dependent antibodies in two patients with neutrophenia and successful treatment with granulocyte-colony-stimulation factor. Transfusion 1999; 39: 527-30.

11. Zernikow B, Friedrichsdorf S, Wamsler C, Michel E: Schmerztherapie und palliative Versorgung krebskranker Kinder (Deutsche Ausgabe der WHO-Empfehlungen „Cancer pain relief and palliative care in children") Datteln, Vestische Kinderklinik Datteln- Universität Witten/Herdecke, 2002.

12. Evers S, Pothmann R, Überall MA, Naumann E, Gerber W-D: Therapie idiopathischer Kopfschmerzen im Kindesalter. Empfehlungen der Deutschen Migräne- und Kopfschmerzgesellschaft. Schmerz 2002; 16: 48-56.

13. Kopfschmerzklassifikationskomitee der International Headache Society: Die internationale Klassifikation von Kopfschmerzerkrankungen. Nervenheilkunde 2003; 22: 531-670.

14. Lewis DW, Ashwal S, Dahl G et al.: Practice parameter: Evaluation of children and adolescents with recurrent headaches: Report of the Quality Standards Subcommittee of the American Academy of Neurology and the Practice Committee of the Child Neurology Society. Neurology 2002; 59: 490-8.

15. Hamalainen ML, Hoppu K, Valkeila E, Santavuori P: Ibuprofen or acetaminophen for the acute treatment of migraine in children: a doubleblind, randomized, placebo-controlled, crossover study. Neurology 1997: 48: 103-7.

16. Silver S, Gano D, Gerretsen P: Acute treatment of paediatric migraine: A meta-analysis of efficacy. Journal of Paediatrics and Child Health 2008; 44:3-9.

\section{Functional abdominal pain}

Children with functional abdominal pain show characteristic features. More than half of those affected have other types of pain such as headache and chest pain. Chronic abdominal pain can rarely be explained in monocausal terms.

\section{Somatoform pain disorders}

Cognitive-behavioral therapy combined with training for parents is promising. For severe life impairment, inpatient multimodal pain therapy is recommended. 
17. Hermann C, Kim M, Blanchard EB: Behavioral and prophylactic pharmacological intervention studies of pediatric migraine: An exploratory meta-analysis. Pain 1995; 60: 239-56.

18. Trautmann E, Lackschewitz H, Kroner-Herwig B: Psychological treatment of recurrent headache in children and adolescents - a metaanalysis. Cephalalgia 2006; 26: 1411-26.

19. Damen L, Bruijn J, Verhagen AP et al.: Prophylactic treatment of migraine in children. Part 2. A systematic review of pharmacological trials. Cephalalgia 2006; 26(5): 497-505

20. Apley H, Hale B: Children with recurrent abdominal pain; a field survey of 1000 school children. Arch Dis Child 1958; 33: 165-70.

21. Drossman DA: The functional gastrointestinal disorders and the Rome III process. In: Drossman DA, Corazziari E, Delvaux M, Spiller R, Talley NJ, Thompson WG, et al. (eds.): Rome III: The functional gastrointestinal disorders. 3rded. McLean, VA: Degnon Associates, 2006: 1-30.

22. Drumm B, Koletzko S, Oderda G: Helicobacter pylori infection in children: A consensus statement. European Paediatric Task Force on Helicobacter pylori. J Pediatr Gastroenterol Nutr 2000; 30: 207-13.

23. American Academy of Pediatrics Subcommittee on Chronic Abdominal Pain, North American Society for Pediatric Gastroenterology Hepatology and Nutrition: Chronic abdominal pain in children. Pediatrics 2005; 115: e370-81.

24. Huertas-Ceballos A, MacArthur C, Logan S: Dietary interventions for recurrent abdominal pain (RAP) in childhood. Cochrane Database Syst Rev 2002;(2):CD003019. D0l: 10.1002/14651858.CD003019

25. Lesko SM, Louik C, Vezina RM, Mitchel AA: Asthma morbidity after the short-term use of ibuprofen in children. Pediatrics 2002; 109: E20-3.

Corresponding author

PD Dr. med. Boris Zernikow

Vodafone Stiftungsinstitut für Kinderschmerztherapie

und Pädiatrische Palliativmedizin

Vestische Kinder- und Jugendklinik

Universität Witten/Herdecke

Dr.-Friedrich-Steiner-Str. 5

45711 Datteln, Germany

B.Zernikow@Kinderklinik-Datteln.de

\section{Further Information}

This article has been certified by the North Rhine Academy for Postgraduate and Continuing Medical Education.

Deutsches Ärzteblatt provides certified continuing medical education (CME) in accordance with the requirements of the Chambers of Physicians of the German federal states (Länder). CME points of the Chambers of Physicians can be acquired only through the Internet by the use of the German version of the CME questionnaire within 6 weeks of publication of the article. See the following website:

\section{www.aerzteblatt.de/cme}

Participants in the CME program can manage their CME points with their 15-digit "uniform CME number" (einheitliche Fortbildungsnummer, EFN). The EFN must be entered in the appropriate field in the www.aerzteblatt.de website under "meine Daten" ("my data"), or upon registration. The EFN appears on each participant's CME certificate.

The solutions to the following questions will be published in volume 37/2008. The CME unit "Urticaria: It's HistoryBased Diagnosis and Etiologically Oriented treatment" (volume 25/2008) can be accessed until 1 August 2008.

For volume 33/2008 we plan to offer the topic "The Diagnosis and Treatmene of Primary Osteoporosis According to Current Guidelines."

Solutions to the CME questionnaire in volume 21/2008: Ukena D, Fishman L, Niebling W-B; Bronchial Asthma: Diagnosis and Long-Term Treatment in Adults: 1/a, 2/b, 3/b, 4/a, 5/d, 6/b, 7/d, 8/c, 9/a, 10/c

For e-references please see: www.aerzteblatt-international.de/ref08m511 e-boxes: www.aerzteblatt-international.de/article08m511 
Question 1:

Pain associated with acute otitis media is common. In what range does the medium pain intensity lie on a scale of 0 to $10(0=$ no pain, $\mathbf{1 0}=$ maximal pain)?
a) $2-3$
b) $3-4$
c) $5-6$
d) $7-8$
e) $9-10$

Question 2:

Which of the following principles is important

for preventing the development of a pain memory?

a) Antibiotic treatment should be initiated for immediate pain relief in acute diseases such as otitis media.

b) Postoperatively, especially after bone fractures, older children (above 10 years) need analgesics more often than young children.

c) Postoperatively, pharmacological pain treatment is needed only for infants after painful locally limited procedures.

d) Sufficient pain prevention is necessary for a single, very painful procedure in children of every age.

e) Pain prevention before medical procedures is only necessary for children aged two years or more, since younger patients no longer remember the pain.

Question 3:

What is the gold standard of qualitative and quantitative pain measurement for school age children?
a) Verbal self-reporting
b) Independent observer
c) Electromyography
d) Neurological examination
e) Sensitivity test

Question 4:

What is the procedure for postoperative pain measurement?

a) Postoperative pain in children should usually be assessed by asking the parents because children cannot accurately judge their pain themselves.

b) Postoperative pain measurement should be done once daily.

c) In children up to four years of age, systematic observation of pain related behavior is unnecessary to assess their pain.

d) In children who cannot express themselves in German, an independent assessment of their pain is also appropriate over four years of age.

e) A systematic pain assessment is impossible in sedated patients.

Question 5:

From what age onwards at the earliest should a face scale for selfassessment of pain intensity be integrated into pediatric care, taking into account the child's developmental status and previous experience?
a) From two years of age onwards
b) From four years of age onwards
c) From five years of age onwards
d) From three years of age onwards
e) From seven years of age onwards

Question 6:

Which drug is recommended in international guidelines to treat acute attacks of childhood migraine?

a) Dihydroergotamine

b) Ergotamine c) Ibuprofen

d) Tramadol

e) Metoprolol

Question 7:

Which regional anesthesiological technique can be used in an extensive abdominal surgical procedure in children as part of balanced perioperative analgesia?
a) Caudal anesthesia
b) Peridural anesthesia
c) Brachial plexus blockade
d) Subpubic penile block
e) Intrathecal opioids

Question 8:

Migraine attacks are generally triggered by normal everyday stress. What should be remembered when treating migraine attacks?

a) Pharmacological prophylaxis is necessary for children suffering from migraine.

b) Pharmacological attack therapy should only be started if dietary interventions alone have failed

c) Besides pharmacological attack therapy, cognitive-behavioral training and endurance sport are important.

d) Paracetamol is superior to ibuprofen in the oral treatment of migraine attacks.

e) Pharmacological treatment is superfluous for attacks lasting less than two hours.

Question 9:

How should opioids be administered in newborns, infants, and children with pre-existing cerebral impairment?

a) Treatment should be started with a low initial dose and further doses should be titrated according to response.

b) The starting dose depends on the patient's height and further doses should be based on the child's age.

c) Treatment should be started with a high initial dose and continued with a maintenance dose.

d) The starting dose corresponds to the usual starting dose for children (body weight $>10 \mathrm{~kg}$, age $>6$ months) and the intervals between the opioid doses should be short in this patient population.

e) The starting dose corresponds to the usual starting dose for children (body weight $>10 \mathrm{~kg}$, age $>6$ months) and is continuously increased.

Question 10:

What applies for the bio-psycho-social model for functional abdominal pain in childhood?

a) In functional abdominal pain, an inherited or acquired vulnerability interacts with external stressors.

b) Excessive anxiety of parents, a Helicobacter pylori infection or aversion to school are the commonest causes of functional abdominal pain in children.

c) If functional abdominal pain has developed, the pain experience decreases the child's vulnerability.

d) Lactose loading is the key factor in the development of functional abdominal pain.

e) Cognitive-behavioral therapy cannot influence the course. 


\section{Pain Therapy in Children and Adolescents}

Boris Zernikow, Tanja Hechler

\section{e-REFERENCES}

e1. Howard RF: Current status of pain management in children. JAMA 2003; 290: 2464-9.

e2. Roth-Isigkeit A: Zur Epidemiologie von anhaltenden und/oder wiederkehrenden Schmerzen bei Kindern. Monatsschr Kinderheilkd 2006; 154: 741-54.

e3. Feldman W: Evidence-based Pediatrics. Hamilton, London, Saint Louis, B.C. Decker Inc., 2000.

e4. Hayden GF, Schwartz RH: Characteristics of earache in children with acute otitis media. Am J Dis Child 1985; 1398: 721-3.

e5. Burke P, Bain J, Robinson D, Dunleavy J: Acute red ear in children: controlled trial of non-antibiotic treatment in general practice. Br Med J 1991; 303(6802): 558-62.

e6. Eccleston C, Crombez G, Scotford A, Clinch J, Connell H: Adolescent chronic pain: Patterns and predictors of emotional distress in adolescents with chronic pain and their parents. Pain 2004; 108: 221-9.

e7. Goubert L, Eccleston C, Vervoort T, Jordan A, Crombez G: Parenta catastrophizing about their child's pain. The parent version of the Pain Catastrophizing Scale (PCS-C): A preliminary validation. Pain 2006; 123: 254-63.

e8. Flor $\mathrm{H}, \mathrm{Knost} \mathrm{B}$, Birbaumer $\mathrm{N}$ : The role of operant conditioning in chronic pain: An experimental investigation. Pain 2002; 95: 111-8.

e9. Brna P, Dooley J, Gordon K, Dewan T: The prognosis of childhood headache: A 20-year follow-up. Arch Ped Adoles Med 2005; 159 1157-60.

e10. Jones GT, Silman AJ, Macfarlane GJ: Are common symptoms in childhood associated with chronic widespread body pain in adulthood? Results from the 1958 British Birth Cohort Study. Arthritis Rheum 2007; 55: 1669-75.

e11. Hotopf M, Carr S, Mayou R, Wadsworth M, Wessely S: Why do children have chronic abdominal pain, and what happens to them when they grow up? Population based cohort study. Br Med J 1998; 316(7139): 1196-200.

e12. Walker LS, Guite JW, Duke M, Greene JW: Recurrent abdominal pain: A potential precursor of irritable bowel syndrome in adolescents and young adults. J Pediatr 1998; 132: 1010-5.

e13. Campo JV, Di Lorenzo C, Chiapetta L, Bridge J, Colborn DK, Gartner JCJ et al.: Adult outcomes of pediatric recurrent abdominal pain: Do they just grow out of it? Pediatrics 2001; 108: E1.

e14. Denecke H, Hünseler C: Messen und Erfassen von Schmerz. In: Zernikow B, (ed.): Schmerztherapie bei Kindern. Berlin, Heidelberg, New York: Springer 2005; 45-7.

e15. Cohen LL, Lemanek K, Blount RL, Dahlquist LM, Lim CS, Palermo TM et al.: Evidence-based Assessment of Pediatric Pain . J Pediatr Psychol 2007; November 17, 2007: 1-17.

e16. Berde CB, Sethna NF: Analgesics for the treatment of pain in children. N Engl J Med 2002; 347: 1094-113.

e17. Labouvie H, Kusch M, Bode U: Psychologische Interventionen bei akuten Schmerzen im Kindesalter. In: Zernikow B (ed.): Schmerztherapie bei Kindern. Berlin: Springer 2005; 132-42.

e18. Lönnqvist PA, Morton NS: Postoperative analgesia in infants and children. Br J Anaesth 2005; 95: 59-68.

e19. Mantzke US, Brambrink AM: Paracetamol im Kindesalter: Aktueller Wissensstand und Hinweise für einen rationalen Einsatz zur postoperativen Analgesie. Anaesthesist 2002; 51: 735-46. e20. Moiniche S, Romsing J, Dahl JB, Tramer MR: Nonsteroidal antiinflammatory drugs and the risk of operative site bleeding after tonsillectomy: a quantitative systematic review. Anesth Analg 2003; 96: 68-77.

e21. Krishna S, Hughes LF, Lin SY: Postoperative hemorrhage with nonsteroidal anti-inflammatory drug use after tonsillectomy: a metaanalysis. Arch Otolaryngol Head Neck Surg 2003; 129: 1086-9.

e22. Jeyakumar A, Brickman TM, Williamson ME, Hirose K, Krakovitz P, Whittemore $\mathrm{K}$ et al.: Nonsteroidal anti-inflammatory drugs and postoperative bleeding following adenosillectomy in pediatric patients. Arch Otolaryngol Head Neck Surg 2008; 134: $24-7$.

e23. Doyle E, Robinson D, Morton NS: Comparison of patient-controlled analgesia with and without a background infusion after lower abdominal surgery in children. Br J Anaesth 1993; 71: 670-3.

e24. Morton NS: Management of postoperative pain in children. Arch Dis Child Educ Pract Online 2007; 92: ep14-ep19.

e25. American Academy of Pediatrics: The Assessment and Management of Acute Pain in Infants, Children and Adolescents. Pediatrics 2001; 108: 793-7.

e26. Mazoit J, Dalens BJ: Ropivacaine in infants and children. Curr Opin Anaesthesiol 2003; 16: 305-7.

e27. Sillanpää M, Anttila P: Increasing prevalence of headache in 7year-old schoolchildren. Headache 1996; 36: 466-70.

e28. Rossi LN, Vajani S, Cortinovis I, Spreafico F, Menegazzo L: Analysis of the International Classification of Headache Disorders for diagnosis of migraine and tension-type headache in children. Dev Med Child Neurol 2008; 50: 305-10.

e29. Özge A, Bugdayci R, Sasmaz T, Kaleagasi H, Kurt 0, Karakelle A et al.: The sensitivity and specificity of the case definition criteria in diagnosis of headache: a school-based epidemiological study of 5562 children in Mersin. Cephalalgia 2002; 22: 791-8.

e30. Überall M, Wenzel D: Intranasal sumatriptan for the acute treatment of migraine in children. Neurology 1999; 52: 1507-10.

e31. Winner P, Rothner AD, Saper J, Nett R, Asgharnejad M, Laurenza A et al.: A randomized, double-blind, placebo-controlled study of sumatriptan nasal spray in the treatment of acute migraine in adolescents. Pediatrics 2000; 165: 989-97.

e32. Ahonen K, Hämäläinen ML, Rantala H, Hoppu K: Nasal sumatriptan is effective in treatment of migraine attacks in children: A randomized trial. Neurology 2004; 62: 883-7.

e33. Winner P, Rothner AD, Wooten JD, Webster C, Ames M: Sumatriptan nasal spray in adolescent migraineurs: a randomized, doubleblind, placebo-controlled, acute study. Headache 2006; 46: 212-22.

e34. Tfelt-Hansen P: Triptans vs Other Drugs for Acute Migraine. Are There Differences in Efficacy? A Comment. Headache 2008; 48: $601-5$.

e35. Winner P, Pearlman EM, Linder SL, Jordan DM, Fisher AC, Hulihan J: Topiramate Pediatric Migraine Study Investigators. Topiramate for migraine prevention in children: a randomized, double-blind, placebocontrolled trial. Headache 2005; 45: 1304-12.

e36. Winner P, Gendolla A, Stayer C, Wang S, Yuen E, Battisti WP et al.: Topiramate for migraine prevention in adolescents: a pooled analysis of efficacy and safety. Headache 2006; 46: 1503-10.

e37. Sorge F, De Simone R, Marano E, Nolano M, Orefice G, Carrieri P: Flunarizine in prophylaxis of childhood migraine. A double-blind, placebo-controlled, crossover study. Cephalalgia 1988; 8: 1-6. 
e38. Sorge F Marano E: Flunarizine v. placebo in childhood migraine. A double-blind study. Cephalalgia 1985; 5 (Suppl 2): 145-8.

e39. Ludvigsson J: Propranolol used in prophylaxis of migraine in children. Acta Neurol Scand 1984; 50: 109-15.

e40. Forsythe WI, Gilles D, Sills MA: Propanolol (.Inderal“) in the treatment of childhood migraine. Development Medicine \& Child Neurology 1984; 26: 737-41.

e41. Olness K, MacDonald JT, Uden DL: Comparison of self-hypnosis and propranolol in the treatment of juvenile classic migraine. Pediatrics 1987; 79: 593-7.

e42. Berger T, Damschen U: Rezidivierende Bauchschmerzen. In: Zernikow B (ed.): Schmerztherapie bei Kindern. Heidelberg: Springer 2005.

e43. Crushell E, Rowland M, Doherty M, Gormally S, Harty S, Bourke B et al.: Importance of parental conceptual model of illness in severe recurrent abdominal pain. Pediatrics 2003; 112: 1368-72.

e44. Weydert JA, Ball TM, Davis MF: Systematic review of treatments for recurrent abdominal pain. Pediatrics 2003; 111: e1-e11.

e45. Remschmidt H, Schmidt M, Poustka F: Multiaxiales Klassifikationsschema für psychische Störungen des Kindes- und Jugendalters nach ICD-10 der WHO. Bern, Hans Huber, 2006.

e46. Dobe M, Damschen U, Reiffer-Wiesel B, Sauer C, Zernikow B: Dreiwöchige stationäre multimodale Schmerztherapie bei Kindern und Jugendlichen mit chronischen Schmerzen. Schmerz 2006; 20: $51-60$

e47. Hechler T, Dobe M, Kosfelder J et al.: Effectiveness of a three-week multimodal inpatient pain treatment for children and adolescents suffering from chronic pain: Statistical and clinical significance. Clin J Pain 2008; in Press.

e48. Halpern SM, Fitzpatrick R, Volans GN: Ibuprofen toxicity. A review of adverse reactions and overdose. Adverse Drug React Toxicol Rev 1993; 12: 107-28.

e49. Rainsford KD, Roberts SC, Brown S: Ibuprofen and paracetamol: Relative safety in non-prescription dosages. J Pharm Pharmacol 1997; 49: 345-76.

e50. Bradley RL, Ellis PE, Thomas P, Bellis H, Ireland AJ, Sandy JR: A randomized clinical trial comparing the efficacy of ibuprofen and paracetamol in the control of orthodontic pain. Am J Orthod Dentofacial Orthop 2007; 132: 511-7.

e51. Ali S, Klassen TP: Ibuprofen was more effective than codeine or acetaminophen for musculoskeletal pain in children. Evid Base Med 2007; 12: 144

e52. Silver S, Gano D, Gerretsen P: Acute treatment of paediatric migraine: A meta-analysis of efficacy. J Paed Child Health 2008; 44: 3-9. Epub 2007 Sep 14

e53. Ulinski T, Guigonis V, Dunan 0, Bensman A: Acute renal failure after treatment with non-steroidal anti-inflammatory drugs. Eur J Pediatr 2004; 163: 148-50.

e54. Stanford EA, Chambers CT, Craig KD: A normative analysis of the development of pain-related vocabulary in children. Pain 2005; 114: 278-84

e55. Harbeck C, Peterson L: Elephants dancing in my head: A developmental approach to children's concepts of specific pains. Child Dev 1992; 63: 138-49.

e56. Chen X: Growing up in a collectivistic culture: Socialization and socio-emotional development in Chinese children. In: Comunian AL, Gielen UP, (eds.): International perspective on human development. Lengerich, Italy: Pabst Science Publishers 2000; 331-53.

e57. von Baeyer CL, Marche TA, Rocha EM, Salmon K: Children's memory for pain: Overview and implications for practice. J Pain 2004; 5: $241-9$.

e58. Kokki H, Lintula H, Vanamo K, Heiskanen M, Eskelinen M: Oxycodone vs placebo in children with undifferentiated abdominal pain: a randomized, double-blind clinical trial of the effect of analgesia on diagnostic accuracy. Arch Pediatr Adolesc Med 2005; 159: 320-5.

e59. Evers S: Controlled trials in pediatric migraine: Crossover versus parallel group. Curr Pain Headache Rep 2007; 11: 241-4. e60. Goodenough B, Kampel L, Champion GD, Laubreaux L, Nicholas MK, Ziegler JB et al.: An investigation of the placebo effect and age-related factors in the report of needle pain from venipuncture in children. Pain 1997; 72: 383-91.

e61. Klinger R, Soost S, Flor H, Worm M: Classical conditioning and expectancy in placebo hypoalgesia: A randomized controlled study in patients with atopic dermatitis and persons with healthy skin. Pain 2007; 128: 31-9.

e62. Tait AR, Voepel-Lewis T, Malviya S: Factors that influence parents assessments of the risks and benefits of research involving their children. Pediatrics 2004; 113: 727-32.

e63. Flor H, Hermann C: Schmerz. In: Flor H, Birbaumer N, Hahlweg K, (eds.): Grundlagen der Verhaltensmedizin. Göttingen: Hogrefe 1999; 249-330.

e64. Raquin A, Di Lorenzo C, Forbes D, Guiraldes E, Hyams JS, Staiano A et al.: Childhood functional gastrointestinal disorders: child/adolescent. Gastroenterology 2006; 130: 1527-37. 


\section{CONTINUING MEDICAL EDUCATION}

\section{Pain Therapy in Children and Adolescents}

Boris Zernikow, Tanja Hechler

\section{e-BOX 1}

\section{Pain perception in children}

From about three years of age onwards, children are capable of expressing their pain in concrete terms (e54).

The notion of pain (causes and assessment) follows Piaget's stages of cognitive development (e55).

From the "concrete operational stage" (the stage from which childhood thought is predominantly bound to specific events) onwards, children are capable of forming concepts about causes of pain.

As regards recall processes, Chen (e56) has demonstrated that children at the age of three years are already able to remember painful procedures.

Von Baeyer et al. have described four different ways in which children handle memories of pain (e57):

- Habituation

- No change through the memory

- No memorization pattern

- Sensitization which can take place at the physiological and psychological level, for example by the formation of anxiety-triggered avoidance behavior

Reinforcing factors include operant mechanisms such as increased parental attention when pain occurs. 
e-BOX 2

\section{Additional information on administration of placebos in pediatric pain therapy}

It is common practice at German pediatric centers to administer short infusions with NaCL $0.9 \%$ or oral placebos (especially vitamin C) to children thought to be "feigning pain." If the children show marked pain reduction, this may result in the treating team feeling justified in their belief that the pain reported by the child does not have a "biological" but rather a "psychological" origin. The fact is overlooked that up to $50 \%$ of persons with extremely severe pain (children and adults with migraine attacks, postoperatively, acute abdomen, etc.) show a 50\% placebo induced pain reduction (e58-e60). Placebo administration often leads to pain reduction which can, however, be explained in terms of factors such as classical conditioning processes or expectation effects (e61). Despite these effects, placebo use in children and adolescents can lead to loss of trust not only among children and adolescents but also parents (e62).

If a placebo is administered to an affected child as a means of distinguishing between "biological" and "psychological" pain, this contradicts the scientifically established fact that pain is always to be understood as being of bio-psycho-social etiology (e63). Giving placebo in response to a child's expressions of acute pain provides no information about the underlying causes of the pain, can prejudice the relationship between the treating physician, patient and parents and also prevents the use of an adequate multimodal pain therapy in which psychological elements are an important component (1). Giving a placebo may for a brief period of time free the treating team from its inability to deal professionally with the child's expressions of pain, but usually does not lead to a positive solution of the underlying conflict - the child is expressing pain and wants pain therapy; I as the treating person do not believe he is in pain and do not wish to give him analgesic therapy - but is more likely to further exacerbate this conflict. Particularly when the treating person perceives a child's expressions of pain appear inadequate in relation to the triggering cause (severe pain, small blood sample), inconsistent with the child's behavior (reporting maximum pain rating but "smiling child," complaints of severe headache and wish to play at the computer) or occurring only at certain times (headache on Mondays; in the evening severe postoperative pain but active play behavior during the day), the team should understand the expression of pain as a "message" that is important to understand and which warrants a professional response (e46) - and not the administration of a placebo.

\section{e-BOX 3}

\section{Indication for cranial MRI ${ }^{\star 1}$}

Cranial MRI is indicated for recurrent headache in the following cases:

- Neurological evaluation shows abnormalities

- Simultaneous presence of cerebral seizures

- Changes in headache intensity, frequency or characteristics

- Morning headache

- Nausea/vomiting on awakening

- Nausea between migraine attacks

- Nocturnal headache

- Sudden severe, first-onset headache

- Other additional signs of illness (e.g. changes in personality) suggesting another neurological condition

${ }^{* 1}$ modified from Lewis et al. (14) 


\section{ROME III criteria for classification of recurrent abdominal pain in}

childhood (e64)*1

- Functional dyspepsia

The following criteria must be fulfilled at least once per week for at least two months:

1. Persistent or recurrent pain centered in upper abdomen (above umbilicus)

2. Not relieved by defecation or associated with change in form or frequency of bowel action (this means that no irritable bowel syndrome is present)

3. No signs of inflammatory, anatomical, metabolic or neoplastic process that would explain the patient's symptoms

\section{- Irritable bowel syndrome}

The following criteria must be fulfilled at least once per week for at least two months:

1. Abdominal discomfort (an unpleasant sensation not described as pain) or pain associated for $25 \%$ of the time or more with two or more of the following criteria:

- Improvement with defecation

- Change in frequency of stool

- Change in form or appearance of stool

2. No signs of inflammatory, anatomical, metabolic or neoplastic process that would explain the patient's symptoms

\section{- Abdominal migraine}

All of the following criteria must be fulfilled at least twice in the last 12 months:

1. Paroxysmal episodes of intense periumbilical pain lasting 1 or more hours

2. Healthy in between for weeks or months

3. Pain interferes with normal activities

4. Pain associated with two or more of:
a. Loss of appetite
b. Nausea
c. Vomiting
d. Headache
e. Photophobia
f. Pallor

5. No signs of inflammatory, anatomical, metabolic or neoplastic process that would explain the patient's symptoms

- Functional abdominal pain

The following criteria must be fulfilled at least once per week for at least two months:

1. Episodic or continuous abdominal pain

2. Insufficient criteria for other functional gastrointestinal disorders

3. No signs of inflammatory, anatomical, metabolic or neoplastic process that would explain the patient's symptoms

\section{- Functional abdominal pain syndrome of childhood}

The criteria for functional abdominal pain of childhood must be fulfilled for at least $25 \%$ of the time and include at least one of the following points:

1. Interferes with normal activities

2. Additional somatic symptoms (headache, limb pain, sleep difficulty)

*1 modified from Raquin A, Di Lorenzo C, Forbes D et al.: Childhood functional gastrointestinal disorders: child/adolescent. Gastroenterology 2006; 130: 1527-37 